\title{
LA NEUTRALIDAD LIBERAL COMO ANTIPERFECCIONISMO*
}

\section{LUIS VILLAVICENCIO MIRANDA*}

RESUMEN: En este trabajo se examina críticamente el concepto de neutralidad liberal en la versión de Rawls y las principales vías para justificarla, deteniéndose especialmente en el argumento escéptico, el argumento de la igualdad y el argumento de la autonomía. Luego, se sostiene que el argumento de la autonomía es el que mejor explica la neutralidad liberal entendida como antiperfeccionismo. Y, para terminar, se revisa la pertinencia y relevancia de algunos reproches que pueden hacerse contra el antiperfeccionismo liberal.

PALABRAS CLAVE: Liberalismo - neutralidad - antiperfeccionismo justicia como equidad - autonomía.

\section{THE LIBERAL NEUTRALITY AS ANTIPERFECTIONISM}

ABSTRACT: it will be critically analyzed the concept of liberal neutrality according to the version of Rawls and the main ways to justify it, with particular attention to the skeptical, equality and autonomy arguments. Then, it is argued that the autonomy argument is the best one to explain the liberal neutrality understood as antiperfectionism. Finally, it will be we reviewed the relevance and significance of some criticisms that can be made against the liberal antiperfectionism.

KEY WORDS: Liberalism - neutrality - antiperfectionism - justice as fairness - autonomy.

\section{1) INTRODUCCIÓN}

En términos generales, y antes de hacer distinciones más finas, la neutralidad liberal se sustenta fundamentalmente en su carácter deon-

Fecha de recepción: 20 de junio de 2012.

Fecha de aceptación: 20 de septiembre de 2012.

** Doctor en Derecho por la Universidad Autónoma de Madrid (España). Profesor de la Escuela de Derecho de la Universidad de Valparaíso (Chile) y de la Universidad Diego Portales (Santiago de Chile). 
tológico, esto es, en la defensa de la tesis de que el concepto del deber y lo justo están por sobre la idea del bien ${ }^{1}$. De este modo, la justicia como equidad se caracteriza por ser tolerante y encontrarse abierta a que las personas puedan adoptar, en ejercicio de su autonomía, las concepciones del bien que sean más congruentes con sus planes de vida particulares. El comportamiento más recto y equitativo que puede alcanzar un agente moral consiste, entonces, en respetar los principios de la justicia, facilitando que todos y cada uno de los sujetos busquen, alcancen, persistan o abandonen la idea del bien que les parezca más excelsa o convincente.

Esta forma de entender la neutralidad se conecta directamente, en el plano de la fundamentación, con una postura no escéptica en cuestiones de metaética teórica, pero restringida exclusivamente al diseńo de las instituciones sociales básicas, que es, como se recordará, el objeto de la teoría de la justicia. Y esto se vincula con la defensa de la distinción entre la moralidad pública y privada, puesto que si el problema de la justicia atañe exclusivamente a la estructura básica de la sociedad, su alcance se restringe a lo que tradicionalmente se engloba, al interior del liberalismo, dentro del ámbito de lo público, apartándose de las concepciones del bien que cada persona procure alcanzar. Solo de esta forma la justicia como equidad puede asegurar que, en la vida efectiva de una comunidad, se desplieguen todas las nociones del bien que expresan el pluralismo propio de las sociedades democráticas modernas; pero en el marco de las opciones definidas al interior de un conjunto de derechos y deberes previamente determinados $y$, por ende, dispuestos con independencia de cualquier concepción del bien, única forma de asegurar adecuadamente la autonomía de las personas. En fin, este reconocimiento de la autonomía, equitativamente distribuida entre todos los seres humanos, supone que la teoría de la justicia depende de una concepción de la persona como agentes morales libres e iguales.

El objetivo de este trabajo es analizar críticamente, por un lado, el concepto de neutralidad liberal, tal como ha sido concebido dentro de esa tradición de pensamiento, deteniéndome con cierta atención -aunque no exclusiva ni exhaustivamente- en la versión que del mismo ideó Rawls a lo largo de su producción intelectual; y, por otro, las principales formas de justificar la tesis de la neutralidad liberal. Para lograrlo, en primer lugar, describiré con cierto rigor analítico el concepto de neutralidad. En segundo lugar, revisaré las diferentes formas que permitirían fundamentar la neutralidad liberal. Y, para terminar, avanzaré algunas conclusiones.

Rawls, John (1971): A Theory of Justice. Oxford University Press, $\$ 6$. 


\section{2) LA NEUTRALIDAD. UNA NOCIÓN AMBIGUA Y EQUÍVOCA}

Al contrario de lo que pudiera creerse, el liberalismo no reclama para sí una neutralidad en todos los niveles, por lo que es forzoso aclarar su sentido y alcance. Lo central es comprender que el liberalismo no defiende un sistema político que sea neutral en todos los aspectos. Así pues, por ejemplo, un Estado neutral, que ampara el derecho de sus ciudadanos a adoptar y persistir en una determinada concepción del bien, no es indiferente entre un fundamentalista integrista y un religioso liberal, porque salvaguarda el principio de secularización del Estado -o, más específicamente, la imposibilidad de imponer una determinada moral beata por medio del ordenamiento jurídico- que el religioso liberal se muestra proclive a aceptar. Tampoco trata de la misma manera a un hombre promiscuo sexualmente y a un violador. Con estas ilustraciones quiero resaltar la siguiente cuestión fundamental: el liberalismo no defiende la neutralidad estatal en asuntos de justicia o de derechos; al contrario, su tesis es que la justificación y legitimidad de la organización política pende precisamente de la protección y reconocimiento de los derechos individuales, y esto es lo que permite amparar la libertad religiosa y la libertad sexual, pero proscribir al activista fundamentalista y al violador. La neutralidad no opera respecto de los derechos y la justicia, sino sobre las cuestiones relativas al bien, o sea, aquellos juicios sobre lo que hace buena o valiosa una vida en particular. Es más, la ausencia de imparcialidad recién apuntada le impone al Estado el deber de ser neutral respecto al bien con miras a tratar de un modo equitativo a sus ciudadanos ${ }^{2}$.

Los ejemplos señalados permiten aclarar que "incluso en el caso de aquellas cuestiones como las concepciones del bien respecto a las cuales el Estado liberal ha de mantenerse neutral, la neutralidad requerida no es una neutralidad en relación a los efectos. Un Estado que proteja los derechos de las personas tendrá como efecto favorecer unas formas de vida y no otras, aunque la justificación de su acción sea neutral en el sentido de que no hace referencia a juicios sobre los méritos relativos de esas diferentes formas de vida" 3 . Es decir, aunque efectivamente el Estado puede intentar evitar que alguien perpetre una violación basándose en la libertad sexual de la potencial víctima y no basándose en el juicio de que la forma de vida de un violador es peor de la de quien no lo es, la consecuencia es idéntica: la neutralidad de la justificación no será imparcial con relación a los efectos. Esta ausencia de neutralidad no constituye un problema para el liberalismo, puesto que lo justo tiene prioridad sobre lo bueno y, por

\footnotetext{
2 Mulhall, Stephen y Swift, Adam (1996). El individuo frente a la comunidad. El debate entre liberales y comunitaristas. Traducción de Enrique López Castellón. Madrid: Ediciones Temas de Hoy, p. 62.

3 Mulhall / Swift (1996) 62.
} 
ende, los derechos que el Estado ampara prevalecen sobre las concepciones del bien que las personas puedan decidir para sí. En suma, el liberal defiende dos tesis básicas: i) un Estado debe ser neutral respecto de las concepciones del bien, aunque exclusivamente en relación con la justificación y no a los efectos; y b) un Estado no ha de ser neutral en cuestiones relativas a la justicia o a los derechos.

Como se ve, la neutralidad estatal se vincula directamente con uno de los temas más ampliamente discutidos en la filosofía del Derecho, esto es, las relaciones entre el Derecho y la moral o, más precisamente, la cuestión de la imposición de la moral por medio del sistema jurídico. Ahora bien, si el liberalismo no es neutral en todos los casos, tampoco sostiene una separación entre el Derecho y la moral en todos los planos. Pero si esto es así, ¿no nos enfrentamos a una paradoja? ¿Cómo es posible defender la neutralidad moral por medio de una tesis moral? La neutralidad estatal "parece ilusoria desde un principio en la medida en que se trata de una tesis moral, en respuesta a una cuestión moral, y solo defendible desde argumentos morales. Parece que estamos ante la contradicción de proponer un planteamiento o principio moral como justificación y criterio de la acción del estado y, a la vez, pretender la independencia o neutralidad moral de esa propuesta" 4 .

Pero este contrasentido solo es aparente. No se trata de defender la postura de la absoluta independencia del Estado de principios morales sino, por el contrario, de determinar cuáles son aquellos principios que deben observarse al momento de delimitar el ámbito de regulación del derecho. Como dice MacCormick, el "punto a discutir no es entonces si debería utilizarse el poder del Estado de acuerdo con principios morales, sino qué principios morales deberían observarse en el ejercicio del poder del Estado" 5 . Dicho en otros términos, lo que el liberalismo se abstiene de

4 Colomer, José Luis (1998). "Libertad personal, moral y derecho. La idea de la 'neutralidad moral' del Estado liberal". En La justicia en el derecho privado y en el derecho público. Anuario de la Facultad de Derecho de la Universidad Autónoma de Madrid, No 2, p. 91.

5 Para graficar la disparidad entre ambos puntos, MACCоRміск recurre a la siguiente analogía: "Supongamos que estamos discutiendo sobre la práctica correcta de la psiquiatría. Un punto de vista podría ser el de que, al tratar a los pacientes, un psiquiatra debería abstenerse de hacer juicios morales sobre -o prescripciones morales para- su paciente, y solo debería tratarlo con el objetivo de restaurar su salud. Otro punto de vista podría ser el de que, al tratar a los pacientes con vistas a restaurar su salud, el psiquiatra debe aplicar una concepción moral relativa a qué es la salud. Ambas perspectivas serían puntos de vistas morales (puntos de vista 'éticos') sobre qué es lo que le concierne moralmente hacer al psiquiatra. La primera sostiene que el psiquiatra está moralmente obligado a no hacer referencia a valores morales al tratar a sus pacientes. La segunda sostiene que el psiquiatra está moralmente obligado a referirse a valores morales al tratar a sus pacientes. Desde ambas perspectivas, un buen psiquiatra es aquel que observa cierto principio moral cuando actúa como terapeuta; pero únicamente desde la segunda perspectiva debería realizarse la terapia mediante la referencia a lo que se considera que son valores morales para el paciente". MaCCormick, Neil (1998). "En contra de la ausencia de fundamento moral". Traducción de María Lola Gon- 
hacer es aplicar por medio del derecho una determinada moral positiva, aunque sí pretende imponer, echando mano a argumentos intersubjetivamente válidos claro está, una determinada moral crítica o ideal y no cualquiera -como se verá- sino aquella que respeta la autonomía de la persona. Precisar que el liberalismo cree tener buenas razones para imponer una específica moral crítica, es fundamental a la hora de enfrentar aquellos discursos que, supuestamente fundados en la tolerancia simplona del relativismo cultural, reclaman para sí igual validez que el liberalismo. Lo relevante son las razones que se sostengan para defender una determinada tesis moral, esta en ningún caso puede fundarse en las propias creencias subjetivas, sino que debe cumplir las exigencias de la universalidad e imparcialidad o, seamos más modestos, al menos pretenderlas ${ }^{6}$.

La distinción entre moral positiva o social y moral crítica o ideal, a la que aludía más arriba, es clave para entender cabalmente que la neutralidad estatal no es independiente de cierto tipo de argumentos morales. La primera alude a las reglas y los principios éticos socialmente predominantes en una sociedad determinada; la segunda, en cambio, se refiere a aquellas reglas y principios que buscan la satisfacción de criterios intersubjetivos de universalidad e imparcialidad. Pues bien, dos cosas me interesa resaltar:

a) la neutralidad que reclama el liberalismo sostiene que no es una razón legítima apoyarse en la moral positiva para sancionar jurídicamente una acción, esto es, en la circunstancia de que la conducta que se busca castigar se considera inmoral de conformidad con las convicciones éticas mayoritariamente compartidas, o en virtud de que socava las creencias y valores que singularizan y constituyen a una determinada sociedad, enfrentándolo directamente con el moralismo legal imperfecto ${ }^{7}$ y con cier-

zález Soler. En VÁzQuez, Rodolfo (compilador): Derecho y moral. Ensayos sobre un debate contemporáneo. Barcelona: Gedisa, p. 161.

6 Garzón Valdés, Ernesto (2000). Instituciones suicidas. Estudios de ética y política. México D.F.: Paidós Universidad Nacional Autónoma de México, pp. 200-208.

La expresión moralismo legal admite, según Feinberg, dos sentidos: es perfecto cuando postula la prohibición de alguna conducta por el hecho de constituir en sí misma una inmoralidad; en cambio, es imperfecto cuando, no estableciendo la inmoralidad per se de un acto, este se prohíbe con el objeto de imponer la moral positiva. En la famosa disputa entre Hart y Devlin, este último defendía un moralismo legal imperfecto, ya que justificaba la incorporación de pautas morales en el ordenamiento jurídico en virtud de que estas sustentaban la cohesión social y la comunidad tenía el derecho a defender su integridad, que podía verse afectada por conductas «inmorales» que desintegrarían su unidad. Si esto es así, el moralismo legal imperfecto de Devlin puede ser justificado por aplicación del principio del dańo, lo que prueba, dicho sea de paso, la inutilidad de este principio por sí solo que exige, para ser provechoso, una adecuada delimitación del concepto de daño. Véase MaLEm, Jorge (1998). "La imposición de la moral por el derecho. La disputa Devlin-Hart". Traducción de María Lola González Soler. En VÁzquez, Rodolfo (compilador): Derecho y moral. Ensayos sobre un debate contemporáneo. Barcelona: Gedisa, pp. 59-79. 
tas vertientes del comunitarismo ${ }^{8}$. Sin embargo, el liberalismo sí sostiene que es posible condenar una determinada acción a través del ordenamiento jurídico si esta lesiona valores propios de una moral crítica o ideal; y

b) la conexión entre la apelación a los criterios de una moral crítica o ideal y la proscripción del perfeccionismo en cualquiera de sus variantes -según el cual el poder coactivo del Estado debe orientarse a la promoción de algunas formas de vida específicas que se consideran más valiosas que otras en razón de principios morales- no es necesaria ni directa, como sí lo es la incompatibilidad entre la adhesión a una moral crítica o ideal y la defensa del moralismo legal imperfecto y algunas formas de comunitarismo. Es más, algunos autores liberales, como Raz ${ }^{9}$, pretenden compatibilizar el liberalismo con alguna forma de perfeccionismo ${ }^{10}$. No voy a referirme aquí a la posibilidad de fundar un perfeccionismo liberal, solo quiero enfatizar, por medio de esta acotación, que la neutralidad estatal no solo no es moralmente neutra, sino que sería compatible con varias formas de concebir la moral crítica o ideal. Parafraseando a Laporta, lo que debe hacerse no es, como podría parecer a primera vista, desmoralizar el derecho sino deslegalizar la moral ${ }^{11}$.

Para facilitar la comprensión de lo que hemos dicho hasta ahora y, por ende, identificar con precisión en qué sentido el liberalismo pretende ser neutral y en qué acepciones no, presentemos los diferentes modos de entender la neutralidad por medio del cuadro que sigue ${ }^{12}$.

8 Claramente, por ejemplo, la tesis particularista defendida por Walzer. Véase WALzER, Michael (1993). Las esferas de la justicia. Una defensa del pluralismo y la igualdad. Traducción de Heriberto Rubio. México D.F.: Fondo de Cultura Económica, pp. 17-43. Raz, Joseph (1986). The Morality of Freedom. Oxford University Press.

10 Para ver un detallado análisis de la posibilidad de justificar liberalmente una doctrina perfeccionista, véase Colomer, José Luis (2001). "Autonomía y gobierno. Sobre la posibilidad de un perfeccionismo liberal". En Doxa, Cuadernos de Filosofía del Derecho, Universidad de Alicante, No 24, pp. 251-296.

11 Laporta, Francisco (1989). "Ética y derecho en el pensamiento contemporáneo". En CAmps, Victoria (editora), tomo III. Barcelona: Crítica, p. 255.

12 Rawls, John (1996). El liberalismo politico. Traducción de Antoni Domènech. Barcelona: Crítica, pp. 224-229. Véase también del mismo autor (2002). La justicia como equidad. Una reformulación. Traducción de Andrés de Francisco. Barcelona: Paidós, pp. 205-210. Sobre las diversas formas de entender el principio de neutralidad puede verse KyмLicKa, Will (1989): "Liberal Individualism and Liberal Neutrality". Ethics, Volumen 99, N 4, pp. 883905; Farrell, Martín Diego (1994): "Algunas maneras de entender la neutralidad". Doxa, Cuadernos de Filosofía del Derecho, Universidad de Alicante, No 15-16, 1994, pp. 179-197; Mulhall, Stephen y Swift, Adam (2003). "Rawls and Communitarianism". En Freeman, Samuel (editor): The Cambridge Companion to Rawls. Cambridge University Press, pp. 460487; y Pérez de la Fuente, Óscar (2005). La polémica liberal comunitarista. Paisajes después de la batalla. Madrid: Dykinson, pp. 66-72. 


\begin{tabular}{|c|c|c|c|}
\hline Denominación & Concepto de neutralidad & $\begin{array}{l}\text { Neutralidad liberal } \\
\text { (rawlsiana) }\end{array}$ & Neutralidad no liberal \\
\hline $\begin{array}{l}\text { Neutralidad } \\
\text { procedimental }\end{array}$ & $\begin{array}{l}\text { Aquella teoría moral que } \\
\text { pretende justificar sus pos- } \\
\text { tulados sin apelar a ningún } \\
\text { valor moral. }\end{array}$ & & $\begin{array}{l}\text { Según Rawls es imposi- } \\
\text { ble alcanzarla pues toda } \\
\text { teoría de la justicia es } \\
\text { una concepción moral. }\end{array}$ \\
\hline $\begin{array}{l}\text { Neutralidad } \\
\text { de efectos o de } \\
\text { influencia }\end{array}$ & $\begin{array}{l}\text { Ninguna acción política } \\
\text { debe llevarse a cabo si au- } \\
\text { menta la probabilidad de } \\
\text { que una persona pueda } \\
\text { promocionar una u otra } \\
\text { concepción del bien o sus } \\
\text { oportunidades de realizar } \\
\text { dicha concepción. En otras } \\
\text { palabras, el Estado debe } \\
\text { abstenerse de cualquier ac- } \\
\text { tividad que incremente la } \\
\text { posibilidad de que los indi- } \\
\text { viduos acepten una doctri- } \\
\text { na particular en detrimento } \\
\text { de otras. }\end{array}$ & & $\begin{array}{l}\text { El respeto de las liberta- } \\
\text { des básicas iguales tiene } \\
\text { consecuencias no neu- } \\
\text { trales, por ejemplo, pro- } \\
\text { mover modos de vida } \\
\text { liberales. Del mismo } \\
\text { modo, la distribución } \\
\text { de esas libertades no } \\
\text { favorece de igual forma } \\
\text { la prosecución de las } \\
\text { distintas concepciones } \\
\text { del bien. }\end{array}$ \\
\hline $\begin{array}{l}\text { Neutralidad } \\
\text { de propósitos } \\
\text { (primera in- } \\
\text { terpretación) }\end{array}$ & $\begin{array}{l}\text { El Estado debe asegurar a } \\
\text { todos los ciudadanos igua- } \\
\text { les oportunidades de pro- } \\
\text { mover cualquier concep- } \\
\text { ción del bien libremente } \\
\text { defendida por ellos. }\end{array}$ & & $\begin{array}{l}\text { El liberalismo no es } \\
\text { neutral respecto de las } \\
\text { personas que persiguen } \\
\text { concepciones del bien } \\
\text { irrazonables. }\end{array}$ \\
\hline $\begin{array}{l}\text { Neutralidad } \\
\text { de propósitos } \\
\text { (segunda in- } \\
\text { terpretación) }\end{array}$ & $\begin{array}{l}\text { Ninguna acción política } \\
\text { puede ser llevada a cabo } \\
\text { o justificada sobre la base } \\
\text { que promueve un ideal } \\
\text { del bien, ni sobre la base } \\
\text { que permite a los indivi- } \\
\text { duos perseguir un ideal del } \\
\text { bien. Luego, el Estado debe } \\
\text { abstenerse de cualquier ac- } \\
\text { tividad que favorezca direc- } \\
\text { tamente a una concepción } \\
\text { particular del bien. }\end{array}$ & $\begin{array}{l}\text { La neutralidad de pro- } \\
\text { pósitos pretende que } \\
\text { las políticas públicas } \\
\text { puedan ser respaldadas } \\
\text { por todas las ciudada- } \\
\text { nas y ciudadanos en } \\
\text { razón de que compar- } \\
\text { ten una misma con- } \\
\text { cepción normativa de } \\
\text { la justicia. Política an- } \\
\text { tiperfeccionista. A esta } \\
\text { se refiere Rawls. }\end{array}$ & \\
\hline
\end{tabular}

\section{3) LA JUSTIFICACIÓN DE LA NEUTRALIDAD}

De ello quiero ocuparme ahora: ¡cuáles son los principios morales que justifican la neutralidad estatal para el liberalismo? En términos generales, el liberalismo ha recurrido a tres tipos de argumentos para justificar la neutralidad estatal. Haré referencia a cada uno de ellos para luego con- 
centrarme en el último, que debe considerarse como el decisivo para el liberalismo ${ }^{13}$.

\section{1.) EL ARGUMENTO ESCÉPTICO}

El primero de los argumentos desplegados es el denominado argumento escéptico. Según este, no es posible determinar racionalmente que ciertos modos de vida o valores morales sean más rectos que otros $\mathrm{y}$, por lo tanto, el Estado no encuentra ningún soporte legítimo para imponer a sus ciudadanos algunos fines en detrimento de otros, dejando en libertad de acción a las personas para adoptar las concepciones del bien y principios morales que estimen convenientes. El problema inmediato de este razonamiento es que nos lleva más lejos de lo deseable, ya que si no es posible discutir sobre cuestiones morales, tampoco es posible fundamentar la neutralidad liberal puesto que esta descansa necesariamente en premisas éticas. Así pues, este argumento se enfrenta inevitablemente a la paradoja de la tolerancia y es incapaz de escapar del obstáculo que desploma al escepticismo metaético radical como una tesis plausible: si no puede sustentarse cualquier opción valorativa como válida, tampoco es posible justificar la neutralidad liberal.

Sin embargo, hay una posibilidad de rescatar esta línea argumental mediante la defensa ya no de un escepticismo general, sino de uno de carácter selectivo. Según esta perspectiva, la imposibilidad de deliberar -en términos lógicamente compulsivos- sobre asuntos éticos solo se extiende a las concepciones personales de la vida buena y el bien, pero no sobre los asuntos propios de la moralidad política. Este escepticismo selectivo desemboca en la conocida tesis de la discontinuidad entre la vida privada y pública y, entonces, el argumento escéptico puede ser reformulado del siguiente modo: como no podemos discernir y jerarquizar, conforme a razones intersubjetivas, cuáles ideales que orientan las vidas de las personas son valiosos o mejores que otros $-\mathrm{y}$ considerando que la moral positiva en las sociedades democráticas modernas se fragmenta de modo cada vez más agudo en múltiples y a veces contrapuestas formas y hábitos de vida-, es necesario diseñar las instituciones sociales y políticas de tal manera que respeten y alienten la mayor diversidad en lo que respecta a los principios del bien y la virtud.

Esta reformulación del argumento escéptico es perfectamente coherente con el liberalismo, particularmente con la distinción entre lo justo y lo bueno y la prioridad de lo primero sobre lo segundo. La base del

13 Colomer (1998) 102-115; y Colomer, José Luis (2002). "Libertad individual y límites del derecho. El liberalismo y sus críticos". En Díaz, Elías y Colomer, José Luis (editores). Estado, justicia, derechos. Madrid: Alianza, pp. 188-193. 
liberalismo rawlsiano radica en sostener que el interés de orden supremo de toda persona consiste en salvaguardar su capacidad de elaborar, evaluar y persistir racionalmente en su propia concepción del bien; y como no es posible identificar las formas de vida más valiosas, la estructura básica de la sociedad debe ser diseñada de tal modo que permita a cada individuo adoptar y modificar sus concepciones del bien y, por último, la posición original debe ser construida de tal forma que refleje adecuadamente estas exigencias. En las propias palabras de Rawls: "los ciudadanos como personas libres tienen derecho a ver sus personas como independientes y no identificadas con ningún sistema particular de fines. Dada su facultad moral de formar, revisar y perseguir racionalmente una concepción del bien, su identidad pública como personas morales y fuentes autooriginantes de pretensiones no se ve afectada por cambios que a lo largo del tiempo se produzcan en sus concepciones del bien, al menos en tanto tales cambios sean en cierto modo continuos y tengan explicaciones adecuadas. Por desgracia estas observaciones son extremadamente vagas; pero su único propósito es indicar la concepción de persona que está conectada con la concepción pública de la justicia en una sociedad bien-ordenada, y por tanto con los principios de justicia aplicables a sus instituciones básicas. Por el contrario, puede que los ciudadanos, en sus asuntos personales o en la vida interna de las asociaciones, consideren sus fines y aspiraciones de otra forma. Puede que tengan apegos y afectos de los que creen que no deberían, o no podrían, distanciarse; y puede que consideren impensable verse a sí mismos sin determinadas convicciones y compromisos religiosos y filosóficos. Pero nada de esto tiene por qué afectar a la concepción de la persona que está conectada con la concepción pública de la justicia y con su ideal de la cooperación social. Dentro de diferentes contextos podemos adoptar puntos de vista diversos acerca de nuestra persona sin incurrir en contradicción, con tal que esos puntos de vista sean coherentes entre sí cuando las circunstancias lo requieran"14.

Los problemas que se vienen encima de inmediato son de dos tipos al menos: en primer lugar, ¿por qué las personas deben ser caracterizadas de este modo y no de otro en la situación inicial de imparcialidad?, ¿por qué debe concebirse a los agentes morales ubicados por encima de sus concepciones del bien, siempre abiertos a revisarlas y modificarlas, y no como sujetos que más que cambiar sus concepciones del bien, solo pueden reconocerse en ellas? ${ }^{25}$; y en segundo lugar, ¿es posible hacer la distinción entre moralidad pública y privada?, ¿se sostiene la tesis de la discontinuidad? Dicho en otros términos, no parece haber ninguna razón

\footnotetext{
14 Rawls, John (1986). Justicia como equidad. Materiales para una teoría de la justicia. Traducción de Miguel Ángel Rodilla. Madrid: Tecnos, p. 163.

15 SAndel, Michael (2000). El liberalismo y los límites de la justicia. Traducción de María Luz Melon. Barcelona: Gedisa, pp. 81-83.
} 
defendible para pensar que es más fácil equivocarse respecto a la definición de la vida buena que respecto a la clase de argumentos morales que gobiernan la acción política ${ }^{16}$. Todos estos inconvenientes obligan a desechar el argumento escéptico o, al menos, reforzarlo con otros.

\section{2.) El ARGUMENTO DE LA IGUALDAD}

La segunda justificación se sustenta en el argumento de la igualdad. Según esta perspectiva, la neutralidad liberal encuentra su fundamento en el reconocimiento de la igualdad moral que existe entre las personas. $\mathrm{Su}$ más célebre defensor ha sido Dworkin, a través de un artículo muy conocido titulado "El liberalismo"17 y algunos de los ensayos reunidos en Los derechos en serio ${ }^{18}$. En "El liberalismo", el filósofo estadounidense postulaba que cierta concepción de la igualdad -que identifica como la concepción liberal de la igualdad- es la fuerza del liberalismo ${ }^{19}$. Conforme a esta concepción, el Estado debe tratar a las personas como iguales, es decir, con igual consideración y respeto.

El esfuerzo de Dworkin se conecta directamente con su objetivo de resolver la contradicción, aparente en su opinión, entre libertad e igual$\mathrm{dad}^{20}$. Según él pueden identificarse dos nociones de la libertad: una infructuosa (la libertad como licencia) y otra provechosa (la libertad como independencia). La primera se refiere al grado en que un individuo se encuentra liberado de restricciones sociales o jurídicas para hacer lo que le plazca. La segunda, en cambio, alude al derecho que posee cada persona de diseñar su propio plan de vida y conducirse según él y, por ende, se vincula con la interdicción de la subordinación moral de una persona bajo otra. Así pues, se vulnera la libertad como independencia cada vez que el Estado privilegia ciertas formas de vida como más virtuosas que otras, lo que implica, a su vez, la tesis de que es posible jerarquizarlas

16 RAz (1986) 160. Buena parte de las objeciones a las que aluden estas preguntas las he revisado en otros lugares. Véanse Villavicencio Miranda, Luis (2007). "La concepción política de la persona y las visiones constitutivas del bien". Ideas y Valores, No 135, pp. 29-49. Disponible en: http://www.scielo.org.co/scielo.php?script=sci_arttext\&pid=S012000622007000300002\&lng=es\&nrm=iso\&tlng=es; y (2009): "Algunas críticas a la idea de razón pública rawlsiana". Revista de Derecho de la Pontificia Universidad Católica de Valparaiso, Volumen 32, No 1, pp. 533-557. Disponible en: http://www.scielo.cl/scielo. php?script $=$ sci_arttext\&pid=S0718-68512009000100015\&lng=es\&nrm=iso\&tlng=es Dworkin, Ronald (1983). "El liberalismo". Traducción de Mercedes Córdoba. Hampshire, Stuart (compilador). En Moral pública y privada. México D.F.: Fondo de Cultura Económica, México D.F., pp. 133-167.

18 Dworkin, Ronald (1984). Traducción de Marta Guastavino. Los derechos en serio. Barcelona: Ariel, especialmente capítulos 11 y 12.

DWORKIN (1983) 135.

DWORKIN (1984) 372-395. 
según su valor. Como se ve, la libertad como independencia se identifica con la igualdad de consideración y respeto.

Ahora bien, continúa Dworkin, postular un derecho a la libertad general carece de sentido, ya que no permite distinguir situaciones cualitativamente diferentes. Piénsese en los siguientes casos: cuando a una persona se le impide expresar sus opiniones se le está restringiendo su libertad, pero lo mismo ocurre cuando se le prohíbe injuriar a otros. Entender la libertad como licencia no permite distinguir ambas situaciones, solo nos informa de la cuestión bastante obvia de que toda norma que limite la libertad debe descansar en algún fundamento, pero no entrega ningún criterio legítimo de cuándo dicho fundamento es correcto, solo admite el argumento circular de que una restricción será ilegítima cuando afecte la libertad. Luego, defender un derecho a la libertad general es absurdo, por lo que solo existe un derecho a libertades restringidas.

Sin embargo, todos estos inconvenientes se superan cuando entendemos la libertad como independencia. En este caso, sí se posee un criterio legítimo para determinar cuándo una limitación es justa y cuando no: tratar a todas las personas conforme a una concepción liberal de la igualdad. Dworkin concluye, entonces, que el "gobierno debe tratar a quienes gobierna con consideración, esto es, como seres humanos capaces de sufrimiento y de frustración, y con respeto, o sea como seres humanos capaces de llegar a concepciones inteligentes de cómo han de vivir su vida, y de actuar de acuerdo con ellas. El gobierno no solo debe tratar a la gente con consideración y respeto, sino con igual consideración y respeto. No debe distribuir bienes u oportunidades de manera desigual, basándose en que algunos ciudadanos tienen derecho a más porque son dignos de mayor consideración. No debe restringir la libertad sobre la base de que la concepción que tiene un ciudadano de lo que es la vida de un grupo es más noble que la de otro o superior a ella. Tomados en conjunto, estos postulados enuncian lo que podríamos llamar la concepción liberal de la igualdad; pero lo que enuncian es una concepción de la igualdad, no de la libertad como licencia"21.

Y tratar a las personas con igual consideración y respeto, exige que el gobierno sea neutral acerca de cómo debe llevarse adelante una buena vida, descartando la otra opción posible que sería que el gobierno no puede tratar a las personas como iguales sin una teoría de lo que debieran ser los seres humanos. O sea, el tratamiento igualitario no podría ser neutral respecto de una teoría sobre lo que es bueno para las personas o sobre 
cómo ha de vivirse una vida digna. Por supuesto, el liberalismo adopta como moral política una concepción del primer tipo ${ }^{22}$.

Con todo, la concepción liberal de la igualdad no es suficiente por sí sola para descartar que el Estado pudiera suscribir algún ideario perfeccionista, destinado a tratar precisamente a las personas con el respeto y la consideración que merecen según los principios éticos de una vida virtuosa. De este modo, los críticos de la neutralidad pueden replicar que la política perfeccionista no se sustentaría en privilegiar las concepciones del bien de algunos en desmedro de otros, sino en razón del disvalor intrínseco de ciertas conductas. $\mathrm{O}$ argumentar que es posible elaborar una versión perfeccionista de la igualdad que sostenga que los individuos son tratados como iguales cuando se les incita, por medio de mandatos jurídicos, a llevar vidas auténticamente buenas o virtuosas, por lo que en esta visión no tendría cabida el derecho a la independencia moral postulado por Dworkin. Conforme a esta réplica, la conclusión es que a partir de la enunciación del principio abstracto de la igualdad no se sigue imperiosamente la neutralidad estatal, sino que se requiere adicionalmente que la noción de igualdad se apoye en lo que es distintivo en la consideración de los seres humanos como iguales, o sea, un valor moral distinto del de la igualdad. Y el propio Dworkin no puede resistirse a esta objeción ya que, al presentar su explicación de la idea de igualdad como una concepción liberal de la misma, se encuentra implícita en ella el valor de la autonomía individual como central en la fijación de lo que es bueno para cada vida humana. Solo si cada persona juzga por sí misma la bondad o rectitud de sus opciones se le estará tratando con igual consideración y respeto ${ }^{23}$. Esta dificultad impone la necesidad de recurrir a una tercera clase de razones que son las que permiten fundamentar la neutralidad estatal, desde la perspectiva del liberalismo, de manera más convincente.

\section{3.) El ARGUMENTO DE LA AUTONOMÍA}

La última línea de razonamiento apela al argumento de la autonomía. Con arreglo a esta tesis, la neutralidad liberal defiende que, digámoslo una vez más, el Estado a través de las normas que componen el ordenamiento jurídico no debe interferir en la elección y valoración de los planes de vida realizados por cada persona, ni siquiera para asegurar la mayor

22 Dworkin (1983) 148-149. La versión más reciente del liberalismo dworkiniano ha abandonado la pretensión de que la neutralidad entre las diferentes concepciones del bien sea un elemento esencial del liberalismo, señalando fundamentalmente que la neutralidad no debe ser considerada como un axioma sino que como un teorema que se deriva de proposiciones más fundamentales. Véase Dworkin, Ronald (2000). Sovereign Virtue. The Theory and Practice of Equality, Harvard University Press, pp. 211-284. 
probabilidad de éxito en esta empresa. Y este principio exige abrazar el valor intrínseco de la autonomía, es decir, que la selección, la apreciación, la confirmación o la modificación, por parte de cada agente, de la concepción de una buena vida tiene mérito en sí mismo, con prescindencia de los contenidos de estas opciones ${ }^{24}$.

Desde esta perspectiva, el fundamento liberal de la neutralidad estatal puede formularse a través de lo que Nino denomina el principio de la autonomía: "siendo valiosa la libre elección individual de planes de vida y la adopción de ideales de excelencia humana, el Estado (y todos los demás individuos) no debe interferir en esa elección o adopción, limitándose a diseñar instituciones que faciliten la persecución individual de esos planes de vida y la satisfacción de los ideales de virtud que cada uno sustente e impidiendo la interferencia mutua en el curso de tal persecución" 25.

De la enunciación de este principio de la autonomía, se sigue que este tiene dos aspectos que pueden distinguirse. El primero reside en valorar positivamente la autonomía de los sujetos en la elección y concreción de planes de vida, según los ideales de excelencia que conforman la moral personal. El segundo consiste en vedar al Estado, y también a otros individuos, cualquier interferencia en el ejercicio de la autonomía ${ }^{26}$. Y cada uno de estos aspectos se conecta con dos dimensiones diversas de la autonomía: una, el principio de la autonomía opera como fundamento de los derechos; $y$, otra, la autonomía funciona como una facultad.

Como fundamento de los derechos, y en líneas gruesas, la autonomía consiste en un atributo de la persona que justifica la construcción de un catálogo de derechos, cuyo fin es la protección de las condiciones que permiten su ejercicio ${ }^{27}$. Desde este punto de vista, la autonomía se vincula con los presupuestos básicos del discurso moral y su regla fundamental puede predicarse como sigue: es deseable que cada agente moral determine su conducta solo por la libre adopción de los principios morales que, después de suficiente reflexión y deliberación, aprecie como válidos ${ }^{28}$. Pero la autonomía también se concibe como una facultad y se identifica, en este sentido, con el reconocimiento moral de que todas las personas poseemos, en idéntica medida, la capacidad para enfrentarnos por nosotros mismos al desafío de nuestras existencias, optar por aquellos planes de vida más coherentes con nuestras convicciones básicas y conducirnos de acuerdo con ese proyecto. De este modo, la autonomía consiste en

Cfr. Colomer (1998) 106-115.

Nino, Carlos (1989). Ética y derechos humanos. Buenos Aires: Astrea, pp. 204-205.

Nino (1980) 229-236.

Álvarez, Silvina (2002). "La autonomía personal". En Díaz, Elías y Colomer, José Luis (editores). Estado, justicia, derechos. Madrid: Alianza, pp. 167-172. 
una concepción del bien de segundo orden ${ }^{29}$, es decir, lo fundamental para todo individuo es que se le permita decidir la forma en que llevará adelante su vida, con independencia del juicio sobre la virtud de tales preferencias. Al concebir de esta forma la autonomía, se está vedando nuevamente cualquier intromisión perfeccionista, o sea, la práctica de vivir será valiosa si se acomete soberanamente, con prescindencia si es desperdiciada en la prosecución de fines que pudieran considerarse -a la luz de otros proyectos-aberrantes, indignos o frívolos.

El razonamiento de Dworkin sobre el valor intrínseco de la autonomía, ilustra claramente la peculiaridad de una concepción de la autonomía no supeditada a la excelencia de las elecciones efectuadas ${ }^{30}$. Según el filósofo, la vida de una persona puede ser juzgada conforme a dos puntos de vista diversos: i) una visión aditiva, esto es, calificarla como virtuosa o infame con exclusión de su opinión al respecto, por lo que los componentes de una vida buena son independientes de su confirmación; y ii) una visión constitutiva, que sostiene que ningún ingrediente puede acrecentar el valor de la vida de una persona, sino solo cuando es percibido como tal por ella misma, o sea, ningún componente favorece el valor de una vida si no concurre una ratificación efectiva por parte del individuo.

Según Dworkin, disponemos de motivos decisivos para preferir este último punto de vista. Aunque yo crea que un muy buen amigo desperdicia su vida, no lo trataré con el respeto debido si le impusiera la adopción de determinados fines con independencia de su voluntad, aun cuando los considere objetivamente virtuosos. Y esto es así, porque la noción aditiva es incapaz de explicar las razones por las cuales una buena vida es definitivamente valiosa para la persona que la vive y, además, es absurdo que alguien pueda llevar una vida mejor si esto acarrea como consecuencia contradecir sus más profundos ideales éticos. Dos ejemplos del autor ayudarán a esclarecer este punto: a) si un misántropo es muy querido pero desprecia el amor de los demás como si no fuera valioso, su vida no vale más la pena por ser querido; y b) no obstante algunos piensen que la religión debe ser parte de una vida bien llevada, ¿podría mejorar la vida de una persona si se le presiona a observar una vida religiosa que no le merece la pena? ${ }^{31}$.

Todavía más, para Dworkin la autonomía se encuentra indisolublemente vinculada al valor intrínseco que solemos otorgar a nuestras vidas

BARrY, Brian (1997). La justicia como imparcialidad. Traducción de José Tosaus Abadía. Barcelona: Paidós, pp. 183-184.

30 Dworkin, Ronald (1993). Ética privada e igualitarismo politico. Traducción de Antoni Domènech. Barcelona: Paidós, pp. 107-122; y 140-154. Del mismo autor véase (1996) La comunidad liberal. Traducción de Claudia Montilla. Santafé de Bogotá: Siglo del Hombre Editores, pp. 147-152. 
en las disputas éticas. Miradas nuestras existencias como un proyecto, como un pentagrama donde debemos poner las notas, se respeta la vida cuando cada ser humano escribe su melodía en la partitura conforme a sus ideales de excelencia humana, es decir, a su propia y particular visión del mundo. Así, a modo de ilustración, si una persona decide no seguir viviendo porque padece una enfermedad irreversible que la condena a estar postrada e inmovilizada y, por lo tanto, solicita a su médico que le practique una eutanasia, respetaremos su vida si cumplimos su voluntad en el último instante de ella, pues, de lo contrario, estaremos atentando gravemente contra la inviolabilidad de su vida, contra su proyecto personal y no la dejaremos apuntar la última nota a la melodía de su vida falseando su obra justo en el momento final de la misma. Respetar el valor intrínseco de la vida es, entonces, fomentar la libertad individual y no la coerción, en favor de un sistema constitucional y de una actitud que nos motive a cada uno de nosotros a adoptar decisiones sobre la vida autónomamente. La libertad es la exigencia capital del autorrespeto: nadie trata su vida como si tuviera un valor intrínseco, a menos que insista en conducirla por sí mismo, en no ser llevado por otras personas a lo largo de ella, sin importar la medida en que las ame, respete o tema. Las decisiones relativas a la vida son las más importantes en la formación y expresión de la personalidad propia. Es por esta razón que el autor estadounidense sostiene que la libertad -y no la coerción- muestra un respeto auténtico por la vida que es inviolable para cada ser humano. De manera que, para ser consecuentes con esta visión, las libertades básicas forman parte de los requisitos mínimos que debemos exigir en una democracia para que se nos respete, genuinamente, lo más sagrado para todos: nuestras propias vidas ${ }^{32}$.

Establecido que el argumento que apela a la autonomía permite justificar de mejor forma la neutralidad estatal y el antiperfeccionismo que caracterizan al liberalismo, es necesario, para ir cerrando este apartado, insistir en la vinculación que hay entre la autonomía y una cierta concepción de la persona en la teoría rawlsiana. Conexión que sustenta, a su vez, la independencia moral que los agentes morales tienen respecto de las concepciones del bien en la posición original, salvo lo que Rawls denomina la teoría tenue o parcial del bien ${ }^{33}$. Paso a revisar, a continuación, esta cuestión importante.

Para el filósofo estadounidense, una constitución política justa es aquella que apoya los principios de la justicia y, por lo tanto, el Estado debe ser comprendido como una asociación compuesta por ciudadanos

\footnotetext{
32 Dworkin, Ronald (1994). El dominio de la vida. Traducción de Ricardo Caracciolo y Víctor Ferreres. Barcelona: Ariel, pp. 311-315.

33 RaWLs (1971) \$\$60-62.
} 
iguales. El Estado no se ocupa de doctrinas filosóficas y religiosas, sino que regula la búsqueda de los intereses morales y espirituales por los individuos de conformidad con los principios con los que ellos mismos estarían de acuerdo en una situación inicial de igualdad ${ }^{34}$. Es evidente que esta forma de entender el diseño de las instituciones sociales básicas supone concebir a la justicia como equidad, como una teoría deontológica. En efecto, la teoría rawlsiana es deontológica porque postula que respetar los dos principios de la justicia es correcto con prescindencia de si acarrea algún bien y, por ende, algo es bueno solo si encaja en alguna forma de vida consistente con los principios de que ya disponemos. De este modo, lo justo es previo a lo bueno ${ }^{35}$. La concepción de la justicia como equidad, en tanto que es una doctrina kantiana -insiste Rawls en su artículo "Unidad social y bienes primarios"-, acepta el presupuesto liberal de que hay muchas concepciones del bien opuestas e inconmensurables, siendo cada una de ellas compatible con la plena autonomía y racionalidad de las personas humanas. "En consecuencia, la unidad de la sociedad y la lealtad de sus ciudadanos para con sus comunes instituciones descansa no en su adhesión a una concepción racional del bien, sino en un acuerdo acerca de qué es justo para dos personas morales libres e iguales con concepciones del bien diferentes y opuestas. Esta concepción de la justicia es independiente de, y previa a, la noción de bondad, en el sentido de que sus principios ponen límites a las concepciones del bien que son admisibles en una sociedad justa" 36 .

Ahora bien, los agentes morales en cuanto son personas libres, se reconocen unos a otros como poseedores de la facultad moral de tener una concepción del bien y esto implica que no se ven a sí mismos como inevitablemente sujetos al ejercicio de la específica concepción del bien y de los fines últimos que en un momento dado han adherido. En vez de eso, se consideran como capaces de revisar y cambiar dicha concepción por motivos razonables y racionales. Por lo tanto, a los ciudadanos se les está permitido distanciarse de sus concepciones del bien y evaluar sus diversos fines últimos ${ }^{37}$. Con todo, los agentes situados en la posición original necesitan motivos para regatear y, por ende, Rawls sostiene que las partes discuten con el fin de promover una concepción débil o tenue del bien: actuando con racionalidad deliberativa, asumen que su bien es aquello que escogerían si tuvieran pleno conocimiento de las consecuencias de sus

RaWls (1971) 212.

Kukathas, Chandran y Pettit, Philip (2004). La teoria de la justicia de John Rawls. Traducción de Miguel Ángel Rodilla. Madrid: Tecnos, p. 64.

RAWLS (1986) 188.

RAWLS (1986) 162. 
elecciones y concluyen que cualquier vida buena necesita una dotación de bienes primarios ${ }^{38}$.

En suma, la teoría rawlsiana, confirmando su carácter neutral y antiperfeccionista, llega a la conclusión "de que los ciudadanos en tanto que personas morales libres e iguales están en libertad de hacerse cargo de sus vidas, y que cada cual ha de adaptar su concepción del bien a la cuota equitativa de bienes primarios que puede esperar. Las únicas restricciones que se imponen a los planes de vida son que su cumplimiento sea compatible con los principios de justicia públicos y que las pretensiones pueden presentarse solo en relación con determinados tipos de cosas (bienes primarios) y en formas admitidas por esos principios. Esto implica que los fuertes sentimientos y las aspiraciones entusiastas por ciertas metas no otorgan, en cuanto tales, una pretensión sobre recursos sociales o una pretensión de diseñar instituciones públicas a fin de alcanzar esas metas" ${ }^{39}$.

\section{4) A MODO DE CONCLUSIÓN}

En las líneas precedentes se ha precisado que la defensa de la prioridad rawlsiana de lo justo sobre lo bueno no supone suscribir todos los sentidos posibles de la neutralidad. El propio filósofo estadounidense se preocupa de aclarar que no es así. Su posición no pretende satisfacer la neutralidad procedimental, no considera posible satisfacer la neutralidad de efectos o influencia, y tampoco busca alcanzar la neutralidad de propósitos en su primera interpretación. Lo único que Rawls procura satisfacer es la neutralidad de propósitos en su segunda interpretación (o neutralidad justificatoria en la terminología de Kymlicka o neutralidad como exclusión de ideales en los términos de Raz). O sea, la primacía de lo justo supone que las instituciones no están normativamente diseñadas para favorecer (aunque de hecho puedan hacerlo) ninguna concepción del bien particular. La justicia como equidad, entonces, incluye determinadas virtudes políticas -las virtudes de la cooperación social equitativa, las virtudes de la civilidad, de la tolerancia, de la razonabilidad y del sentido de equidad-. Pero lo crucial aquí es que la admisión de estas virtudes políticas por parte de la concepción política no implica un Estado perfeccionista comprometido con una doctrina comprehensiva. En definitiva, la primacía de lo justo sobre las concepciones en la teoría de Rawls busca ser una garantía contra un Estado de carácter perfeccionista.

Para terminar quisiera enunciar algunas de las posibles objeciones que podrían hacerse al principio de la neutralidad liberal. Me interesa,

\footnotetext{
38 RAWLS (1971) 395-399.

39 RAWLS (1986) 198.
} 
sobre todo, distinguir dos estrategias diversas que pueden adoptar las críticas, aunque la separación en muchas ocasiones se hace artificial y las posturas se solapan: las perfeccionistas y las más nítidamente comunitaristas. Según las primeras, los liberales otorgarían un protagonismo excesivo a la elección autónoma individual, obviando la trascendencia del valor moral objetivo -no dependiente de las preferencias individuales- de algunas formas de vida o fines que contribuirían a la bondad de una vida además, o incluso con preferencia, del propio juicio y opción de las personas. Las segundas, en cambio, se centran en la negación de la concepción individualista del ser humano, propia del liberalismo, postulando en vez de eso una apelación al papel decisivo que juega en la configuración de la personalidad humana la comunidad a la cual el individuo pertenece. La crítica comunitarista, particularmente en la versión de Sandel, intenta poner en duda tres cosas fundamentalmente: primero, que siempre esté justificado poner entre paréntesis las doctrinas comprehensivas del bien; segundo, que no exista un pluralismo razonable de concepciones políticas de la justicia; y, tercero, que la razón pública excluya las concepciones comprehensivas del bien ${ }^{40}$.

Sobre las tesis perfeccionistas, basta decir aquí que anteponer la calidad del contenido de las elecciones autónomas al valor en sí mismo que supone una elección constitutivamente soberana, tiene profundas consecuencias - para nada triviales- en el modo en que un Estado puede organizar las instituciones sociales básicas y legitimar las políticas públicas que impulsa. Un Estado perfeccionista no encontrará objeciones, por ejemplo, en hallar buenas razones para prohibir el matrimonio entre dos personas del mismo sexo porque choca con un cierto ideal de excelencia humana que constriñe el elenco de elecciones autónomas que vale la pena amparar. Un Estado configurado al modo liberal, en cambio, no encontrará tales razones. Muy por el contrario, negará la opción de prohibir el evento de que dos personas del mismo sexo contraigan matrimonio, pues la elección de planes de vida autónomos es valiosa constitutivamente y no hay intereses de terceros en juego que justifiquen una intromisión legítima en esa esfera soberana.

Ante el segundo grupo de críticas, por su parte, el liberalismo podría responder en los siguientes términos: como el liberalismo solo busca satisfacer la neutralidad entendida como antiperfeccionismo (neutralidad de propósitos en su segundo sentido), no es necesario que las personas pongan siempre entre paréntesis las doctrinas comprehensivas que comparten, pues el método de evitación en que se sustenta la justicia como equidad solo nos exige que las pongamos entre paréntesis cuando no satisfacen la exigencia de apoyarse en razones que todos los ciudadanos y ciudadanas 
puedan aceptar en una situación ideal de deliberación. Luego, las personas pueden incluso argumentar desde sus propias doctrinas comprehensivas cuando discuten asuntos atingentes a la esfera pública, siempre que satisfagan las restricciones impuestas por la teoría de la justicia. Con ello, podemos salvar la primera y la tercera crítica de Sandel. Y, por último, las restricciones impuestas por la teoría de la justicia deben ser respetadas, no porque exista una prioridad objetiva a favor de ella o porque Rawls no piense que pueda haber un desacuerdo razonable sobre diferentes formas de concebir una concepción de la justicia, sino sencillamente porque son la mejor interpretación de ciertas ideas o intuiciones ampliamente compartidas en las democracias constitucionales modernas, especialmente la de que todos los ciudadanos y ciudadanas nos vemos recíprocamente como agentes morales autónomos, libres e iguales, capaces de actuar racional y razonablemente.

\section{Bibliografía}

- Álvarez, Silvina (2002). "La autonomía personal". En DíAz, Elías y Colomer, José Luis (editores). Estado, justicia, derechos. Madrid: Alianza, pp. 153-175.

- Barry, Brian (1997). La justicia como imparcialidad. Traducción de José Tosaus Abadía. Barcelona: Paidós.

- Colomer, José Luis (1998). "Libertad personal, moral y derecho. La idea de la 'neutralidad moral' del Estado liberal". En La justicia en el derecho privado y en el derecho público. Anuario de la Facultad de Derecho de la Universidad Autónoma de Madrid, No 2, pp. 89-129.

_ ______ (2001). "Autonomía y gobierno. Sobre la posibilidad de un perfeccionismo liberal". En Doxa, Cuadernos de Filosofía del Derecho, Universidad de Alicante, No 24, pp. 251-296.

- _ _ _ (2002). "Libertad individual y límites del derecho. El liberalismo y sus críticos". En Díaz, Elías y Colomer, José Luis (editores). Estado, justicia, derechos. Madrid: Alianza, pp. 177-209.

- Dworkin, Ronald (1983). "El liberalismo". Traducción de Mercedes Córdoba. Hampshire, Stuart (compilador). En Moral pública y privada. México D.F.: Fondo de Cultura Económica, México D.F., pp. 133-167.

\footnotetext{
- _ (1984). Traducción de Marta Guastavino. Los derechos en serio. Barcelona: Ariel.

- __________ (1993). Ética privada e igualitarismo político. Traducción de Antoni Domènech. Barcelona: Paidós.

_ _ _ _ _ _ (1994). El dominio de la vida. Traducción de Ricardo Caracciolo y Víctor Ferreres. Barcelona: Ariel.
} 
(1996). La comunidad liberal. Traducción de Claudia Montilla. Santafé de Bogotá: Siglo del Hombre Editores. (2000). Sovereign Virtue. The Theory and Practice of Equality, Harvard University Press.

- Farrell, Martín Diego (1994): "Algunas maneras de entender la neutralidad". Doxa, Cuadernos de Filosofía del Derecho, Universidad de Alicante, No 15-16, 1994, pp. 179-197.

- Garzón Valdés, Ernesto (2000). Instituciones suicidas. Estudios de ética y política. México D.F.: Paidós, Universidad Nacional Autónoma de México, pp. 199-240.

- Kukathas, Chandran y Pettit, Philip (2004). La teoría de la justicia de John Rawls. Traducción de Miguel Ángel Rodilla. Madrid: Tecnos.

- Kymlicka, Will (1989): "Liberal Individualism and Liberal Neutrality". Ethics, Volumen 99, No 4, pp. 883-905.

- Laporta, Francisco (1989). "Ética y derecho en el pensamiento contemporáneo". En CAMps, Victoria (editora), tomo III. Barcelona: Crítica, pp. 221-295.

- MacCormick, Neil (1998). "En contra de la ausencia de fundamento moral”. Traducción de María Lola González Soler. En VÁzQuez, Rodolfo (compilador): Derecho y moral. Ensayos sobre un debate contemporáneo. Barcelona: Gedisa, pp. 160-182.

- Malem, Jorge (1998). "La imposición de la moral por el derecho. La disputa Devlin-Hart”. Traducción de María Lola González Soler. En VÁzQuez, Rodolfo (compilador): Derecho y moral. Ensayos sobre un debate contemporáneo. Barcelona: Gedisa, pp. 59-79.

- Mulhall, Stephen y Swift, Adam (1996). El individuo frente a la comunidad. El debate entre liberales y comunitaristas. Traducción de Enrique López Castellón. Madrid: Ediciones Temas de Hoy.

(2003). "Rawls and Communitarianism". En

Freeman, Samuel (editor): The Cambridge Companion to Rawls. Cambridge University Press, pp. 460-487.

- Nino, Carlos (1989). Ética y derechos humanos. Buenos Aires: Astrea.

- Pérez de la Fuente, Óscar (2005). La polémica liberal comunitarista. Paisajes después de la batalla. Madrid: Dykinson.

- Rawls, John (1971): A Theory of Justice. Oxford University Press.

- ___ (1986). Justicia como equidad. Materiales para una teoría de la justicia. Traducción de Miguel Ángel Rodilla. Madrid: Tecnos.

Antoni Domènech. Barcelona: Crítica.

(1996). El liberalismo politico. Traducción de (2002). La justicia como equidad. Una reformulación. Traducción de Andrés de Francisco. Barcelona: Paidós. 
- Raz, Joseph (1986). The Morality of Freedom. Oxford University Press.

- Sandel, Michael (2000). El liberalismo y los límites de la justicia. Traducción de María Luz Melon. Barcelona: Gedisa.

- Villavicencio Miranda, Luis (2007). "La concepción política de la persona y las visiones constitutivas del bien". Ideas y Valores, No 135, pp. 29-49. Disponible en: http://www.scielo.org.co/scielo. php?script=sci arttext\&pid=S0120-00622007000300002\&lng=es\& nrm=iso\&tlng=es.

- ___ (2009): "Algunas críticas a la idea de razón pública rawlsiana". Revista de Derecho de la Pontificia Universidad Católica de Valparaíso, Volumen 32, No 1, pp. 533-557. Disponible en: http://www.scielo.cl/scielo.php?script=sci arttext\&pid=S071868512009000100015\&lng=es\&nrm=iso\&tlng=es.

- Walzer, Michael (1993). Las esferas de la justicia. Una defensa del pluralismo y la igualdad. Traducción de Heriberto Rubio. México D.F.: Fondo de Cultura Económica. 